\title{
Fetal Jacob Syndrome (47XYY): An Uncommon Association of Fetal Pulmonary Atresia with Ventricular Septal Defect
}

\author{
Nupur Shah
}

\begin{abstract}
Jacob syndrome is a sex chromosome aneuploidy comprising of an extra $Y$ choromosome usually diagnosed late in postnatal life or never diagnosed throughout the life. Its prenatal diagnosis is usually accidental due to lack of specific fetal phenotype. The case presented here is that of a prenatally diagnosed Jacob syndrome associated with pulmonary atresia and ventricular septal defect (PA-VSD) which is an uncommon fetal phenotype, not reported in the literature so far.

Keywords: 47XYY, Fetal ultrasound, Genetic counseling, Jacob syndrome, PA-VSD, Prenatal diagnosis, Pulmonary atresia with VSD, Sex chromosomal aneuploidy.

International Journal of Infertility and Fetal Medicine (2022): 10.5005/jp-journals-10016-1250
\end{abstract}

\section{INTRODUCTION}

Jacob syndrome is a sex chromosome aneuploidy comprising of an extra $Y$ choromosome affecting 1 out of 1,000 males. It is diagnosed late in postnatal life or never diagnosed throughout the life. ${ }^{1,2}$ Prenatal diagnosis is usually accidental due to lack of specific fetal phenotype. Only a handful of prenatal cases have been reported with phenotype pertaining to increased nuchal translucency, skeletal, brain, and heart abnormalities or as an accidental pickup on cell-free DNA testing. ${ }^{3,4}$ The case presented here is prenatally diagnosed Jacob syndrome associated with pulmonary atresia with ventricular septal defect (PA-VSD) which is an uncommon phenotype not reported in the literature so far.

\section{Case Description}

A 29-year-old low risk primigravida was scanned at 32 weeks for a routine well-being wherein following findings were documented: Normal four chamber view of the heart with a large subaortic VSD with overriding aorta ("Y" sign) seen in five chamber view, only two vessels in the three vessel view and an atretic pulmonary valve were noted. Major aorto pulmonary collaterals (MAPCAs) arising from the descending aorta were seen in the longitudinal view. Findings suggested PA-VSD with MAPCA (Figs 1A to C). Normal male genitalia with bilateral testes in situ were seen. Fetal face suggested mild hypertelorism. No other major anomalies were found. The patient had missed her anomaly scan in view of the ongoing COVID pandemic. Nondirective genetic counseling was done keeping in view the advance gestation and high association of PA-VSD with 22q11.2 microdeletion. Amniocentesis was done for chromosomal microarray and karyotype which revealed 47,XYY (Jacob syndrome) (Figs $1 D$ and 2 ). The prognosis of Jacob syndrome with underlying cardiac defect was explained to the parents who then decided to continue the pregnancy expectantly. A full term vaginal delivery was carried out and postnatal echocardiography confirmed the findings. Parents
Department of Fetal Medicine, Paras Bliss Hospital, Panchkula, Haryana, India

Corresponding Author: Nupur Shah, Department of Fetal Medicine, Paras Bliss Hospital, Panchkula, Haryana, India, Phone: +91 9724768637, e-mail: nupurmshah@gmail.com

How to cite this article: Shah N. Fetal Jacob Syndrome (47XYY): An Uncommon Association of Fetal Pulmonary Atresia with Ventricular Septal Defect. Int J Infertil Fetal Med 2022;13(1):34-35.

Source of support: Nil

Conflict of interest: None

opted against pediatric cardiologist interventional management. The child expired at 4 months age.

\section{Discussion}

Jacob syndrome, also known as superman syndrome, is a sex chromosome aneuploidy characterized by an extra $Y$ chromosome. The origin of this $Y$ chromosome is paternal and results from nondisjunction in the second meiotic division ( $84 \%$ of cases) or a postfertilization mitotic error (16\%). It does not result from increased parental age. ${ }^{1}$ Fetal Jacob syndrome does not have a specific phenotype although a few structural associations have been reported. ${ }^{1-3}$ Prenatal cases are usually picked up accidentally on cell free fetal DNA or karyotype/microarray offered for other indications. ${ }^{4}$ The case presented highlights an uncommon association of pulmonary atresia with ventricular septal defect with Jacob syndrome in a male fetus. The mechanism of an extra $Y$ chromosome in causing this cardiac defect is unclear. PA-VSD is reported to be associated with 22q11.2 deletion syndrome in $25 \%$ cases. ${ }^{5}$ Association of PA-VSD with sex chromosomal abnormalities like Klinefelter syndrome (47XXY) has been reported but with Jacob syndrome (47XYY) is not yet reported. ${ }^{5}$ In this case, 22q11.2 deletion syndrome was ruled out by microarray (Fig. 2). In such cases, parents need to be counseled about the prognosis and

() The Author(s). 2022 Open Access This article is distributed under the terms of the Creative Commons Attribution 4.0 International License (https://creativecommons. org/licenses/by-nc/4.0/), which permits unrestricted use, distribution, and non-commercial reproduction in any medium, provided you give appropriate credit to the original author(s) and the source, provide a link to the Creative Commons license, and indicate if changes were made. The Creative Commons Public Domain Dedication waiver (http://creativecommons.org/publicdomain/zero/1.0/) applies to the data made available in this article, unless otherwise stated. 

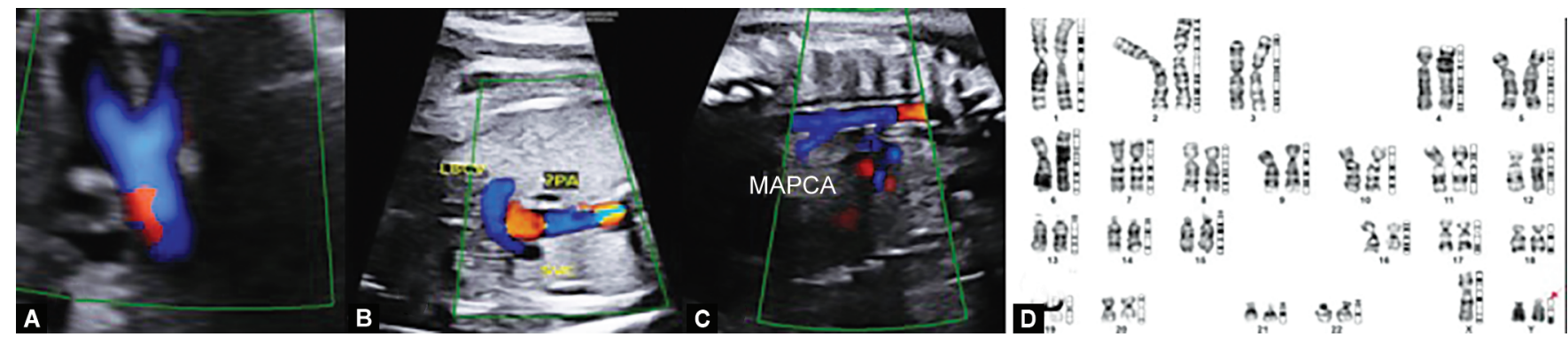

Figs 1 A to D: (A) Five-chamber view showing typical $Y$ sign due to subaortic ventricular septal defect and overriding aorta; (B) Two-vessels in three-vessel view; (C) MAPCA arising from descending aorta; (D) Karyotype showing an extra Y chromosome, 47XYY

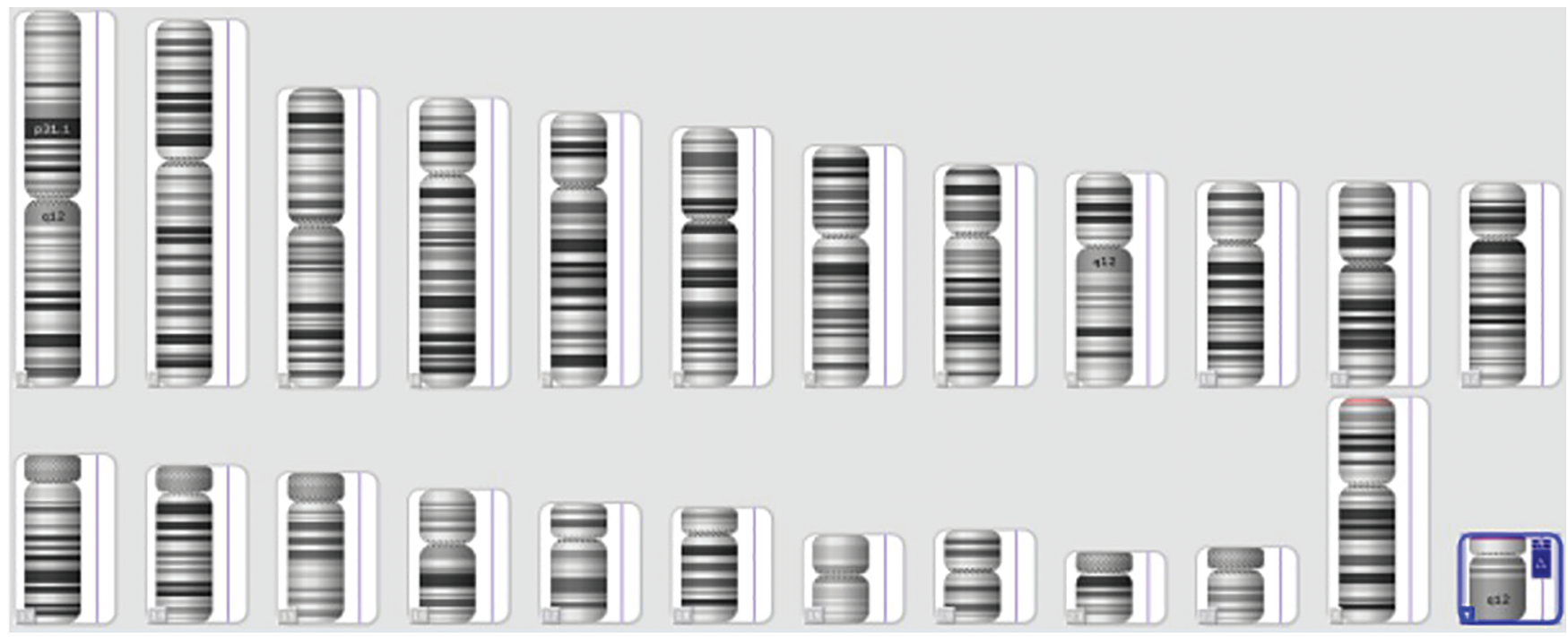

Fig. 2: Chromsomal microarray showing 47XYY-Jacob syndrome

management in context to cardiac defect and in context to the sex chromosomal abnormality. The risk of behavioral problems, autism, language problems, low IQ, and subfertility linked with the chromosomal abnormality were discussed. Parents' decision on continuing or terminating such pregnancies needs to be respected although advance gestation like in this case might be limiting. Risk of recurrence of Jacob syndrome is usually low. ${ }^{1}$ Prenatal diagnostic procedure and early cardiac screening can be offered in subsequent pregnancies.

\section{CONCLUSION}

This case highlights an uncommon association of PA-VSD with Jacob syndrome (47XYY), which underscores importance of a microarray over limited Fluorescence in situ hybridization (FISH) for 22q11.2 deletion in such cardiac anomalies.

What is known?

It is known, that both entities are rare and PA-VSD is commonly associated with 22 q11.2 deletion and uncommonly associated with Klinefelter syndrome (47XXY) in few cases.

What this case report adds?
This case brings an uncommon association of PA-VSD with Jacob syndrome (47XYY) and highlights the importance of chromosomal microarray over limited FISH in these cases.

\section{References}

1. Bianchi DW, Crombleholme TM, D'Alton ME. Fetology: diagnosis \& management of the fetal patient. New York: McGraw-Hill, Medical Pub Division. 2000.

2. Dimitrios A, Christos T, Georgios T, et al. Embryo with XYY syndrome presenting with clubfoot: a case report. Cases J 2009:2:8404. DOI: 10.4076/1757-1626-2-8404

3. Latrech $\mathrm{H}$, Skikar I, Gharbi M, et al. Disorder of sexual development and congenital heart defect in 47XYY: clinical disorder or coincidence? Case Rep Endocrinol 2015,Article ID 802162

4. Zhang B, Lu BY, Yu B, et al. Noninvasive prenatal screening for fetal common sex chromosome aneuploidies from maternal blood. J Int Med Res 2017;45(2):621-630. DOI: 10.1177/0300060517695008

5. Vessel S, Rollings S, Jones A. Prenatally diagnosed pulmonary atresia with ventricular septal defect: echocardiography, genetics, associated anomalies and outcome. Heart 2006;92:1501-1505. DOI: $10.1136 /$ hrt.2005.083295 